\title{
POTENCIALIDADES DEL PILAR EUROPEO DE DERECHOS SOCIALES EN LA PRAXIS JURISPRUDENCIAL DEL JUEZ DE ESTRASBURGO: ENTRE LA HETERARQUÎA VÍNCULO SOCIAL-VÍNCULO ECONÓMICO Y LA DISFUNCIONALIDAD
}

\author{
AINHOA LASA LÓPEZ ${ }^{1}$ \\ Profesora de Derecho Constitucional \\ Universidad de Alicante
}

«En nuestras tierras, los numeritos tienen mejor suerte que las personas. ¿A cuántos le va bien cuando a la economía le va bien? ¿A cuántos desarrolla el desarrollo?».

Los numeritos y la gente. El Libro de los abrazos. Eduardo Galeano (1989).

\section{SUMARIO}

I. Introducción. II. Derechos sociales y forma de Estado Social. III. Constitucionalismo de mercado europeo e integración positiva. IV. La dimensión objetiva de los derechos civiles y políticos en la jurisprudencia del Tribunal Europeo de Derechos Humanos: de la (in)divisibilidad a la accesoriedad. V. Consideraciones finales.

\section{INTRODUCCIÓN}

El 17 de noviembre de 2017, durante la Cumbre social en favor del empleo justo y el crecimiento, celebrada en Gotemburgo, Suecia ${ }^{2}$, el Parlamento Europeo, el Consejo y la Comisión proclamaban, solemnemente, el Pilar Europeo de Derechos Sociales

1 El presente trabajo se inscribe en las actuaciones del proyecto de investigación: «Estado Económico, Capitalismo Financiarizado, Constitución, Gobernanza» (DER2017-84562-P), Investigador principal: Miguel Ángel García Herrera.

2 Cumbre social en favor del empleo justo y el crecimiento: reforzar la dimensión social de la UE. Comisión Europea-Comunicado de prensa. Bruselas, 16 de noviembre de 2017. IP-17-4643-ES-4.pdf. Informe de conclusiones de la Cumbre social en favor del empleo justo y el crecimiento. Disponible en: http://www.government. se/4933fd/contentassets/70800fb59e6c43829c115ca73fb94b6e/concluding-report-gothenburg-summit.pdf (última consulta 13.05.2018). 
$(\text { PEDDSS })^{3}$. Este documento representa el último ensayo a escala europea para tratar de revertir el desafecto de la ciudadanía de la Unión al proyecto de integración, a través de la presunta equiordenación del vínculo social al paradigma del mercado interior. La crisis del capitalismo financiero y sus efectos sistémicos han conducido a recuperar en el espacio institucional, al menos teóricamente, el discurso de la necesaria galvanización de la integración positiva ${ }^{4}$. Ciertamente, la apelación del poder supranacional europeo a la «sofistería» de la cohesión, la igualdad entre mujeres y hombres, la lucha contra el desempleo, la discriminación, la pobreza y exclusión social, está trufada de un tacticismo político que busca paliar el avance imparable de los partidos de extrema derecha en el viejo continente. Los resultados de las elecciones del 25 de septiembre de 2017 al Bundestag, donde Alternativa por Alemania se ha convertido en la tercera formación más votada, reproducen, una vez más, el inquietante escenario político de otros países miembros (Partido de los Daneses en Dinamarca; Fidesz en Hungría; Frente Nacional en Francia; o Amanecer Dorado en Grecia, por citar alguno de ellos).

El impass de la Gobernanza Económica Europea (GEE) y su gestión, apostando por medidas de refuerzo y fortalecimiento de la jerarquía del mercado y sus coordenadas, frente a la expulsión de lo social del relato, ha servido como catalizador para impulsar el acceso de estas formaciones a los parlamentos nacionales reviviendo los fantasmas de periodo de entreguerras. Este descuido intencional de las vindicaciones del derecho a la alteridad del proyecto que encuentra apoyatura en el dogma del mercado y su producción espontánea de bienestar, como una suerte de locus naturalis que alcanza el estatus de racionalidad marginalizando los condicionantes sociales, se ha materializado en la opción, cada vez más ascendente, de la renacionalización de la integración positiva como contrapeso a la supremacía incontestable del vínculo económico, como si el capitalismo financiero se deconstruyese con el simple retorno a la prerrogativa social nacional. En contrapartida, el poder político dominante a escala europea, consciente de la fuerza de la alocución de los derechos sociales, la solidaridad y la justicia social, ha presentado en sociedad el experimento del binomio regulación indirecta - garantías sociales en torno al que se articula el citado PEDDSS.

Este activismo social del establisment europeo emerge paralelo a las dinámicas proactivas del Tribunal de Estrasburgo que, en la última década, han favorecido la lectura objetiva de los derechos civiles y políticos que nutren el Convenio Europeo de Derechos Humanos (CEDH). La vinculación accesoria de ciertos derechos sociales de prestación a los derechos humanos del Convenio ha permitido articular una argumentación que rehúye de la retórica del diferencial de la estructura normativa de los derechos o de la jerarquía del sustrato ideológico, para fundamentar las evidentes conexiones de los determinantes sociales con el efectivo disfrute de los denominados derechos de primera

3 Disponible en: https://ec.europa.eu/commission/sites/beta-political/files/social-summit-european-pillar-social-rights-booklet_es.pdf (última consulta 13.05.2018).

4 En esta óptica se sitúa el Documento de Reflexión sobre la dimensión social de Europa. Comisión Europea COM (2017) 206 de 26 de abril de 2017. Disponible en: https://ec.europa.eu/commission/sites/beta-political/files/ reflection-paper-social-dimension-europe_es.pdf (última consulta 13.05.2018). En él se articulan tres propuestas para el futuro de la integración positiva europea: limitar la dimensión social a la libre circulación o la apuesta por una integración social minimalista (pp. 26-27 del documento); los que desean hacer más en el ámbito social hacen más, esto es, la opción por una Europa social flexible (pp. 28-29 del documento); y, la profundización conjunta de la EU-27 en la dimensión social o la europeización factible de la dimensión social (pp. 30-31 del documento). 
generación. Su consideración de infraestructura necesaria para la garantía efectiva de la estructura primigenia del ser humano, si bien reduce a los derechos sociales a la condición de accesorios permite, por lo menos, soslayar su caracterización como condicionados, propia de los pronunciamientos del juez de Luxemburgo.

La disyuntiva derechos condicionados-derechos accesorios no es baladí. Aunque ambas praxis hermenéuticas despojen a los derechos sociales de sustantividad propia, el razonamiento seguido por uno y otro juez arroja diferencias sustanciales. Para el Tribunal Europeo de Derechos Humanos (TEDH) lo relevante es el mayor o menor grado de afectación a los derechos contemplados por el Convenio que puede suponer la vulneración de un concreto derecho prestacional, que deviene así secundario frente al derecho principal del Convenio ${ }^{5}$. Este razonamiento implicaría, a priori, una desconexión con el dogma del vínculo económico que conecta, a su vez, con la tesis de asistencialización de los derechos sociales con importantes efectos estructurales, como veremos más adelante. Por el contrario, para el Tribunal de Justicia de la Unión Europea (TJUE) lo relevante es el planteamiento económico, único determinante en la caracterización pretoriana de los derechos fundamentales; siguiendo una añeja línea jurisprudencial donde ni siquiera es rastreable la función interpretativa que desempeñaban los derechos sociales. Su funcionalidad al imperativo de la integración económica atenúa, incluso, la eficacia indirecta que pudieran tener los objetivos sociales ${ }^{6}$. Estas divergencias conducen a una contraposición entre las dinámicas sociales pergeñadas por sendos órganos jurisdiccionales que la propia Carta de Derechos Fundamentales de la Unión (CDFUE) no consigue soslayar. El Capítulo IV de la Carta imbuido de una solidaridad remercantilizada, diluye cualquier atisbo de reencuentro con las bases materiales del constitucionalismo social o con la dimensión positiva de la libertad. A esta panoplia habría que añadir la nueva propuesta del Pilar Europeo que se incardina en la estrategia de la futura dimensión social del euro sistema.

Con la finalidad de valorar su contribución a esta dualidad hermenéutica que acompaña a los derechos sociales en uno y otro espacio normativo en las páginas que siguen se abordarán las siguientes cuestiones: en primer lugar, la dependencia de los derechos sociales de la constitución material del Estado social, premisa marginal en la doctrina constitucional mayoritaria que contribuye, sin embargo, a clarificar la significación constitucional de los derechos sociales. En segundo lugar, se hará referencia a los derechos sociales teorizados desde los postulados del constitucionalismo de mercado europeo que terminan por operar su propia desocialización, haciendo especial referencia al PEDDSS. En tercer lugar, se reflexionará sobre los mecanismos articulados por el TEDH para garantizar la dimensión (inautónoma) objetiva de los derechos humanos. A continuación, se pondrán de relieve los puntos de encuentro y desencuentro en las líneas pretorianas sobre derechos sociales articuladas por ambos tribunales europeos para, finalmente, fundamentar la tesis de la inoperancia del Pilar como instrumento de referencia orientativa en la labor de promoción por el TEDH de la cuestión social en los derechos de defensa.

5 López Guerra, Luis (2015): «Crisis económica y Derechos Humanos. Una nota de jurisprudencia», Teoría y Realidad Constitucional, núm. 36, pp. 399-414.

6 Maestro Buelga, Gonzalo (2002): «Constitución económica y derechos sociales en la Unión Europea», Revista de derecho comunitario europeo, núm. 7, p. 143. 


\section{DERECHOS SOCIALES Y FORMA DE ESTADO SOCIAL}

\section{El concepto de derechos fundamentales: una aproximación desde la constitución material del constitucionalismo social}

Los derechos sociales pueden definirse como una categoría normativa consustancial al modelo jurídico político del Estado social, y, como tal, en ellos están presentes las bases materiales del nuevo orden social que esta forma de Estado interioriza ${ }^{7}$. La publificación del conflicto distributivo determina la nueva relación que convierte al Estado en el nuevo receptor de las demandas del capital y del trabajo que dejan de estar radicadas en la esfera de la Sociedad. Empero, el pacto entre las fuerzas dominantes posee una naturaleza lábil y compleja que se reflejará en la naturaleza dual de los derechos sociales, materializando el momento funcional y el del conflicto. Este significado jurídico político de los derechos sociales representa el compromiso del constitucionalismo social con cada uno de los elementos de la relación dialéctica acumulación-legitimación, de ahí su carácter bifronte en el marco de la estrategia de la acumulación del capital. Por una parte, en términos de productividad y crecimiento económico. El carácter prestacional y el contenido económico de los derechos sociales representa el momento funcional a la dinámica económica con la consiguiente participación en la lógica del sistema capitalista. Los derechos sociales no son un coste para el sistema económico, sino que contribuyen a su crecimiento y expansión. En el proceso redistributivo del Estado social se produce una coordinación entre las dinámicas de la demanda y la producción; con la socialización de la inversión se persigue promocionar la reproducción social de la fuerza de trabajo. Al mismo tiempo, con el vínculo relación salarial — régimen de la acumulación se genera un círculo virtuoso entre las capacidades de producción y la progresión de consumo de las clases trabajadoras que favorece la creación de riqueza y su redistribución ${ }^{8}$. Por otra parte, los derechos sociales actúan con carácter funcional a la legitimación del sistema en términos de estabilidad política y adhesión social, en tanto en cuanto desarrollan los contenidos del pacto vertebrados en la generalización de situaciones de bienestar y el reforzamiento de la legitimidad del Estado, manteniendo la cohesión interna de las fuerzas del proletariado que refuerzan su capacidad de movilización para la conquista del derecho al trabajo y, por ende, de la lucha estratégica contra las fuerzas del capitalismo?.

De acuerdo con estas coordenadas, los derechos sociales acusarían en su estructura una cierta dependencia de condicionantes económicos y político-sociales determinantes del carácter dinámico de sus contenidos y que reflejan el momento conflictual de los dere$\operatorname{chos}^{10}$. Esta peculiar fisonomía de los derechos sociales que define la complejidad, el carácter contradictorio y la posición de esta categoría jurídica, ha generado un intenso

7 Gambino, Silvio; Falbo, Alessandro (2017): «Estado social y crisis económica. Los nuevos desafíos del constitucionalismo contemporáneo», Revista de derecho constitucional europeo, núm. 28. LuCiAni, Massimo (1995): «Sui diritti sociali», Studi in onore di Manlio Mazzioti di Celso. Vol. II. Roma: Cedam, p. 114.

8 García Herrera, Miguel Ángel (2004): «I diritti sociali nella vecchia Europa», Quaderni di Rassegna Sindacale, núm. 1, p. 101.

9 De Cabo Martín, Carlos (1986): La crisis del Estado Social. Barcelona: Promociones y Publicaciones Universitarias, PPU, pP. 34-36.

10 Cascajo Castro, José Luis (1988): La tutela constitucional de los derechos sociales. Madrid: Centro de Estudios Constitucionales, p. 30. 
debate a propósito del estatus jurídico de este tipo de derechos, en concreto, si participan del calificativo de fundamentales. Al respecto, las consideraciones para cuestionar la fundamentalidad de los derechos responden a: la defensa de la normatividad en clave jurídico-positiva, el imperativo del cálculo económico, la ruptura de la distribución de competencias poder legislativo - Tribunal Constitucional, y la razón de la impronta ideológica. En todo caso, en estas cuatro causas está presente una lectura de los derechos sociales desconectada de las transformaciones introducidas por la forma de Estado, lo que propicia reflexiones en clave descriptiva que reducen al enunciado constitucional del artículo 1.1 de la Constitución a un mero apunte anecdótico de la sistemática normativa constitucional incapaz de trascender la ortodoxia efectista del método positivista, traducido en el predominio de elementos privatistas y no tanto en la apatía doctrinal a las corrientes comparadas más proclives a la conexión entre generaciones de derechos. Como señala con acierto Juli Ponce, la clave está en tomar en serio la prescriptividad de la forma de Estado social, su autonomía o sustantividad constitucional ${ }^{11}$, frente a la desnaturalización del clausulado social presente en las formulaciones de aquel sector doctrinal que niega a los derechos sociales su carácter de fundamentales o lo condiciona a un previo desarrollo legislativo que termina por aprehender el significado de fundamental. Ello evitaría la deriva de nuestra Carta Magna hacia un texto atemporal apto para la connivencia de todo tipo de modelos jurídico-políticos (sea el constitucionalismo social, sea el constitucionalismo de mercado) con sus consiguientes principios estructurales ordenadores de la convivencia social.

Sin embargo, esta neutralización del constitucionalismo social no significa la negación de un orden socio-político determinado. Al contrario, la directa apelación a la «selección de expectativas individuales y sociales hecha por el constituyente» ${ }^{12}$ implica que la noción de derechos fundamentales responde a un poder constituyente dominante que la patrimonializa, en tanto en cuanto es capaz de hacer valer las «expectativas individuales y sociales» de las que es portador». Y, en lo que atañe al caso español «el proceso constituyente (...) coincide con el despliegue de la crisis económica mundial y con la eclosión de la polémica en torno al Welfare State. De ahí que (...) los debates sobre la revisión del Estado de Bienestar y la tensión entre los principios intervencionistas y neoliberales encontraron, en el marco de las distintas opciones político - constitucionales, un eco especial y dejaron su huella difusa- y, a veces contradictoria —en el texto constitucional» ${ }^{13}$.

En este sentido, la negación no deviene de la manida diferente estructura normativa de los derechos sociales y los derechos civiles y políticos, superando así el iusnaturalismo

11 Ponce Solè, Juli (2017): «Reforma constitucional y derechos sociales: la necesidad de un nuevo paradigma en el derecho público español», Revista Española de Derecho Constitucional, núm. 111, pp. 72-75.

12 Bastida, Francisco J. (2008): «¿Son los derechos sociales derechos fundamentales? Por una concepción normativa de la fundamentalidad de los derechos». Estudios sobre la Constitución Española. Homenaje al profesor Jordi Solé Tura. Vol. II. Madrid: Congreso de los Diputados, pp. 1089-1091.

13 Sastre Ibarreche, Rafael (1996): El derecho al trabajo. Madrid: Trotta, p. 97. En esta misma óptica de consideración de la Constitución española de 1978 como constitución de la crisis que expresa la idea de la interiorización por el dictado constitucional de una serie de elementos que reflejan la revisión de los contenidos característicos del Estado social en clave privatista vid: Morisi, Massimo (1984): «Aspectos esenciales de la relación entre Estado y economía en una Constitución de la crisis», en Predieri, A; García de EnTerría, E. (coord.): La Constitución española de 1978. Madrid: Civitas, pp. 377-421. PonCE Solè, Juli (2017): «Reforma constitucional y derechos sociales: la necesidad de un nuevo paradigma en el derecho público español», cit., p. 73. 
racionalista para el que los derechos de libertad tenían como fundamento la limitación del poder que frenaba toda injerencia pública en la esfera privada que gozaba de plena autonomía. Y, por ello, tales derechos se configuraban al margen de cualquier organización política. En contrapartida, los derechos sociales lejos de participar de esta estructura requerían para su efectiva satisfacción contar con un aparato de servicios y prestaciones públicas de gran complejidad. Partiendo de estas divergencias los derechos de libertad se concebían como fundamentales, mientras que los derechos sociales eran confinados al ámbito infraconstitucional como derechos extraños y ajenos al auténtico código de los derechos del hombre y del ciudadano, tanto desde el punto de vista de su titularidad, en la medida en que no son universales, como desde la perspectiva de la dinámica formal ${ }^{14}$.

La ruptura de estos presupuestos que servían de base a los tradicionales derechos fundamentales, configurados como derechos subjetivos, como consecuencia del nuevo papel de la Constitución como norma jurídica, generaron una depuración conceptual y garantista. La fundamentalidad jurídica distinta de la positivación restringida de las libertades negativas del constitucionalismo liberal encuentra su deber ser en la caracterización de la Constitución como normativa La ruptura con la concepción taumatúrgica de los derechos fundamentales desprovistos, aparentemente, de todo vínculo político con el poder público permite derivar la apostilla de fundamental de la posición suprema del texto fundamental. Ahora bien, argumentada la transición de la metajuridicidad a la juridicidad de los derechos se arguye que esta última no es consecuencia de su consideración como derechos constitucionales (nominalismo simplista), sino de la exclusión de la denominada interpositio legislatoris, y, cumulativamente, de la disponibilidad inmediata del derecho por el/la titular ${ }^{15}$.

No obstante, esta tesis de la fundamentalidad de los derechos adopta como punto de partida una noción de la normatividad limitada en su sentido jurídico-positivo, que resulta contradictoria con el argumento ya expuesto de la «selección de expectativas individuales y sociales hechas por el constituyente», como fundamento legitimador de la fundamentalidad de los derechos ${ }^{16}$. Principalmente, porque la «selección y preferencia por el constituyente» entronca con una concepción de la normatividad en clave jurídico-material, de la dominación política como objeto específico del derecho constitucional. La Constitución como producto de las fuerzas políticas dominantes con capacidad de imponer los intereses/demandas sociales en conflicto a través de su interiorización/positivación que teoriza el momento de la flexibilidad característica del constitucionalismo social y los derechos adscritos a este modelo. La Constitución como fuente de integración, legitimación y garantía del Derecho Constitucional del Estado social ${ }^{17}$.

Cuestión distinta es que la determinación de su configuración constitucional conecte con un constitucionalismo social de la crisis. En todo caso, esta aproximación en clave

14 Diсіотті, Enrico (2004): «Sulla distinzione tra diritti di libertá e diritti sociali: una prospectiva di filosofia analitica», Quaderni Costituzionali, núm. 4, pp. 752 y ss.

15 «Los derechos fundamentales son los recogidos en los Capítulos I y II en cuanto participan de las dos notas básicas del carácter fundamental de los derechos ya mencionadas, la disponibilidad del derecho por su titular y la indisponibilidad de su existencia por el legislador». BASTIDA, Francisco J. (2008): « ¿Son los derechos sociales derechos fundamentales?, cit., p. 1097.

16 Ibídem, pp. 1089-1090.

17 Dogliani, Mario; Massa Pinto, Ilenia (2017): Elementi di Diritto Constituzionale. Torino: Giappichelli, pp. 11-18. 
normativista a la cláusula constitucional de Estado social supone una minusvaloración de esta forma de Estado, porque desde estas valoraciones el Estado social se configura como un principio jurídico que impide derivar efectos relevantes del dictado constitucional. Esta explicación funcionalista de la fundamentalidad de los derechos tiene como resultado una devaluación/neutralización del texto constitucional, al reconducirse la Ciencia Constitucional a un mero tecnicismo funcional.

Por el contrario, nosotros colegimos el carácter de fundamentales de los derechos sociales en base a la defensa del alcance prescriptivo del Estado social alejándonos de las formulaciones constitucionales neutras. El constitucionalismo social transforma la propia caracterización de los derechos como fundamentales, es la forma de Estado el elemento determinante de la fundamentalidad. Concretamente, los derechos sociales emancipados de la condición de minoría jurídica y diversidad institucional a la que habían sido confinados por la dogmática liberal, conforman junto con los derechos de libertad y aquellos políticos el modo de ser de una comunidad a la que la Constitución es inherente, y redefinen el significado de los primeros como derechos de una determinada forma de organización social ${ }^{18}$.

\section{El significado constitucional de los derechos sociales}

Siguiendo las consideraciones desarrolladas en el apartado anterior, la normatividad constitucional de los derechos sociales conecta directamente con la naturaleza pacticia/ transaccional de la Constitución como marco jurídico de integración del conflicto que opera en el Estado Social. Esta define el momento garantista de los derechos sociales, su garantía y protección es la propia de los derechos constitucionales y, como tales, tienen carácter de normas jurídicas vinculantes para la totalidad de los poderes públicos. Por lo tanto, existen como tales derechos independientemente de su desarrollo en una ley, por lo que no estamos en presencia de enunciados programáticos o conceptos en blanco carentes de todo contenido normativo ${ }^{19}$. Antes bien, los derechos sociales expresan el vínculo social que define el aspecto de garantía vinculado a la forma de Estado social que impide su subordinación al mercado. Es decir, a pesar de su dependencia de los recursos disponibles, es su carácter constitucional lo que impide el desconocimiento del derecho. Esta característica es predicable de todas y cada una de las tipologías que integran la categoría de los derechos sociales (derechos de prestación, derechos de participación, derechos a percibir parte de un bien social) ${ }^{20}$.

Frente a esta posición estarían las argumentaciones que defienden que las prestaciones que constituyen el contenido de estos derechos estarían diversificadas con relación a la situación fiscal del Estado, respondiendo a elecciones particulares y selectivas. De modo que los derechos sociales acusarían en su estructura los condicionantes de una

18 Lombardi, Giorgio (1999): «Diritti di libertá e diritti sociali», Politica del Diritto, núm. 1, pp. 7-8. CANTARo, Antonio (2006): Il secolo lungo. Lavoro e diritti sociali nella storia europea. Roma: Ediesse, p. 84.

19 Luciani, Massimo (1995): «Sui diritti sociali», cit., pp. 120-121. Dogliani, Mario (1994): Introduzione al Diritto Costituzionale. Bolonia: Il Mulino, p. 135.

20 Baldassarre, Antonio (1997): Diritti della persona e valori costituzionali. Torino: Giappichelli, pp. 131 132 y $210-213$ 
economía de mercado en evolución y de infraestructuras de tipo administrativo y fiscal ${ }^{21}$. El principal baluarte de estas reflexiones es la expulsión del enunciado social del texto fundamental propiciando una sugestiva adecuación de la Constitución política a la evolución de la estrategia de acumulación del capital.

En este caso, la solución aportada es la de la técnica de la comprensión, que no de la supresión del derecho ${ }^{22}$. O lo que es lo mismo, el hecho de que los límites de la economía no se hayan acompañado de un reconocimiento constitucional de la eficacia jurídica de los derechos ha generado un desequilibrio que propicia un amplio margen de actuación para el derecho viviente que permite que el proceso de ajuste entre derechos sociales y la nueva realidad material constitucional del vínculo económico europeo se realice a través de la interpretación jurídica y la legislación ordinaria. Circunstancia que, paradójicamente, es uno de los principales motivos aducidos por los detractores de la fundamentalidad de los derechos sociales, al situar el dilema de su protección constitucional entre la legitimidad democrática del legislativo y ejecutivo, o la cobertura del juez ordinario y constitucional $^{23}$. A ello habría que añadir que cuando el juez europeo decidió introducir los derechos fundamentales en el orden europeo, recurriendo a la técnica de los principios generales, no se cuestionó que tal decisión pusiera en tela de juicio el criterio de fundamentalidad, ni tan siquiera que este hubiera suplantado la legitimidad y la competencia del poder ejecutivo y legislativo de la Unión. Más bien, se celebró la incorporación de esta categoría como parámetro de validez del derecho comunitario.

De ahí que consideremos insuficientes estas tesis que niegan el significado constitucional de los derechos sociales. Los derechos sociales como derechos vinculados a la forma de Estado social participan de los elementos que la caracterizan. En primer lugar, su carácter constitucional los coloca en una posición privilegiada en contraposición con las exigencias de funcionamiento del sistema económico, legitimando una función correctora con respecto a éste. En segundo lugar, organizan la compatibilidad con el mercado y con el sistema económico sobre la base de su preeminencia normativa, que comporta la prevalencia de la justicia social sobre el funcionamiento del mercado y del sistema económico. Por último, el reconocimiento constitucional de los derechos sociales implica la necesidad para el legislador de permanecer vinculado al dictado constitucional, que los proyecta más allá de las fronteras de la política, de la programaticidad ${ }^{24}$.

21 Por todos vid. Forsthoff, Ernst (1986): «Concepto y esencia del Estado Social de Derecho», en AbENDroth, W; Forsthoff, E; Doenring, K. El Estado Social. Madrid: Centro de Estudios Constitucionales, pp. 69-107.

22 Carmona Cuenca, Encarnación (2008): «¿Los derechos sociales de prestación son derechos fundamentales?». Estudios sobre la Constitución Española. Homenaje al profesor Jordi Solé Tura. Vol. II. Madrid: Congreso de los Diputados, pp. 1109-1111.

23 En esta perspectiva BASTIDA, Francisco J. (2008): «¿Son los derechos sociales derechos fundamentales?, cit., para quien «Los derechos sociales también podrían adquirir ese carácter fundamental por vía jurisprudencial, si su contenido se incluye en la dimensión objetiva de los derechos propiamente fundamentales, pero esto podría entrañar una mutación constitucional tanto de las relaciones constitucionales entre el legislador y los jueces como de la posición de los derechos sociales, si constitucionalmente están concebidos como meros principios rectores de la política social y económica, con exclusión de su eficacia directa», p. 2001.

Para un exhaustivo examen de esta controversia y propuestas de solución véase la interesante obra de Morales, Leticia (2015): Derechos sociales, constitucionales y democracia. Madrid: Marcial Pons.

24 Maestro Buelga, Gonzalo (2006): «I diritti sociali nella Costituzione Europea», Rivista della Sicurezza Sociale, pp. 93-94. 


\section{CONSTITUCIONALISMO DE MERCADO EUROPEO E INTEGRACIÓN POSITIVA}

\section{El oxímoron de los derechos sociales fundamentales de la Unión Europea}

La nueva forma de articulación de las relaciones de poder entre la dimensión estatal y la dimensión económica en el espacio supranacional europeo comporta un nuevo modelo constitucional en el que debemos situar el verdadero alcance de las dinámicas derechos sociales-Unión Europea (UE). Al respecto, podemos señalar que la función de los derechos sociales como parámetros legitimadores de la intervención estatal en la economía desaparece en el imaginario del constitucionalismo de la Unión, evidenciando el momento de confrontación entre derechos sociales y ordenamiento jurídico europeo. Su redefinición desde el espacio de las políticas, no de los derechos, deslegitima su deber ser del constitucionalismo social. El mercado se erige como parámetro de definición de las políticas sociales funcionales a su garantía ${ }^{25}$.

Esta ruptura con los derechos sociales adscritos al Estado social es paradigmática en la construcción del juez europeo del concepto de fundamentalidad. La tutela de los derechos fundamentales se condiciona a los objetivos generales de la integración económica que diluyen la exégesis del concepto. Las consecuencias son especialmente gravosas por lo que a los derechos sociales, ahora meros objetivos, se refiere. Por una parte, la expulsión de los derechos sociales del ámbito constitucional de la Unión. Por otra parte, el sistema pretoriano europeo de tutela de los objetivos sociales los subordina a las exigencias del proceso. La confinación del ámbito de lo social al político al margen de cualquier sujeción normativa redefine el principio de legalidad de la Unión dirigido a la tutela de la fuerza material del mercado y del derecho de la competencia en consonancia con los contenidos formales de las disposiciones de los Tratados. Dada esta contextualización se proscribe una consideración de los derechos sociales como principios generales del Derecho de la Unión (DUE), una desconstitucionalización amplificada con la aceleración de la reforma y fortalecimiento de la Gobernanza Económica Europea (GEE), vínculo económico del proyecto europeo ${ }^{26}$.

El redimensionamiento de la política social a través de su subordinación a las exigencias de la competitividad y la economía de mercado es una constante desde los Tratados Constitutivos de las Comunidades Europeas hasta el actual referente de derecho originario representado por el Tratado de Lisboa. ${ }^{27}$ En la relación derechos sociales intervención pública desde la perspectiva del modelo jurídico-político de la Unión articulado en torno a la centralidad del mercado, la autonomía normativa de tales derechos desaparece. Una economía de mercado abierta y de libre competencia no es aquella en la que el cálculo de los costes y beneficios del funcionamiento de los mecanismos económicos viene incorporado en la valoración de la eficiencia misma del sistema. En esta los

25 Jimena Quesada, Luis (2016): Social rights and policies in the European Union. Valencia: Tirant lo Blanch, pp. $25-26$.

26 Baquero Cruz, Julio (1998): «La protección de los derechos sociales en la Comunidad Europea tras el Tratado de Ámsterdam», Revista de Derecho Comunitario Europeo, núm. 4, pp. 655-656.

27 LASA López, Ainhoa (2012): Los derechos sociales en el constitucionalismo de mercado: aporías de la dimensión social de la Unión Europea. Bilbao: Universidad del País Vasco/Servicio Editorial, pp. 49-146. 
derechos sociales no tienen en el vínculo social el criterio legitimador de su funcionamiento, sino que son juzgados por su capacidad de orientarse y servir al mercado. Su subordinación al mercado implica la pérdida del significado constitucional descrito en el apartado segundo. Y, es paralela a una nueva configuración constitucional, la del constitucionalismo de mercado europeo, donde los objetivos sociales no se contraponen al mercado sino que se subordinan a sus exigencias ${ }^{28}$.

Esta degradación de los derechos sociales a derechos condicionados de compatibilidad subalterna con el mercado vacía de significado la superior preceptividad que les confería la normatividad constitucional del constitucionalismo social, condicionando su actuación y efectividad a las variables macroeconómicas. La pérdida de su estatus constitucional implica la desconstitucionalización de los derechos sociales. El carácter eventual, relegado a los espacios que expresan su compatibilidad con el mercado, define las nuevas bases: funcional al espacio económico y garantista de los principios del constitucionalismo de mercado europeo, a los que se ve confinada la política social. Al mismo tiempo, los condicionamientos de la competitividad aparecen como el vínculo que conecta lo social con la economía desde una doble perspectiva. Por un lado, la dimensión social se define como espacio subordinado a las exigencias del mercado y de la competencia. Por otro lado, la competencia y el mercado interior determinan el nuevo espacio de los derechos sociales, que no es otro que su subordinación a los imperativos de la integración económica. Y esto es así porque la intervención social europea está dirigida no a la creación de un ámbito propio de regulación social, sino al control de los sistemas nacionales para impedir la adopción por éstos de medidas limitadoras del mercado interior. Se sanciona la transferencia de la competencia a lo social, una configuración coherente con la caracterización de la competencia como principio constitutivo de la construcción del mercado interior. En definitiva, el paradigma de la libre competencia comporta la redefinición de la política social en base a su subordinación a las exigencias de la competitividad $^{29}$.

Este estatus marginal y de indefinición de los derechos sociales trató de corregirse con la Carta de Derechos Fundamentales de la Unión Europea (CDFUE), aprobada por las instituciones de la Unión en diciembre del año 2000. Sin embargo, los esfuerzos por superar los límites funcionales del derecho originario, junto a la proclamada indivisibilidad e interdependencia del conjunto de derechos que aglutina la Carta, no han fructificado en una recomposición de las condiciones normativas para una eficaz garantía de los derechos sociales, principalmente, porque la CDFUE se inserta en el modelo constitucional del Estado mercado o Estado economía ${ }^{30}$ distinto al del Estado social.

28 Maestro Buelga, Gonzalo (2006): «I diritti sociali nella Costituzione Europea», cit., pp. 89-125. GarCía Herrera, Miguel Ángel (2002): «Derechos sociales y Tratados comunitarios: evolución normativa», CorCuera Atienza, Javier (Coord.). La protección de los derechos fundamentales en la UE Madrid: Dykinson, pp. 313 y ss.

29 SACHA, Garben (2017): "The Constitutional (Im)balance between 'the Market' and 'the Social' in the European Union», European Constitutional Law Review, núm. 13, pp. 23-61.

30 Para una definición concisa de los principios estructurales que vertebran a esta nueva forma de Estado del poder global de mercado véanse las aportaciones doctrinales de MAESTro BuElga, Gonzalo (2016): «Del Estado social a la forma global de mercado», en García Herrera, Miguel Ángel; Asensi Sabater, José; Balaguer Callejón, Francisco (Coord.). Constitucionalismo crítico. Liber amicorum Carlos de Cabo Martín. Valencia: Tirant Lo Blanch, pp. 53-94. Y, García Herrera, Miguel Ángel (2016): «Estado económico y capitalismo financiarizado: propuestas para un constitucionalismo crítico», en García Herrera, Miguel Ángel; Asensi Sabater, José; 
Conforme a este modelo se asumen como irrelevantes las desigualdades socio-económicas que generan las incertidumbres de la acumulación del capital y se fortalecen las pretensiones del individualismo frente a la ruptura y regresión de la solidaridad colectiva. El objetivo no es acabar con los desequilibrios económico-sociales, sino la protección más incisiva de las esferas de identidad y realización personal asumiendo el interés del individuo frente a las fortalezas de la comunidad-ciudadanía europea.

\section{El Pilar Europeo de Derechos Sociales}

\subsection{Aproximaciones teórico-constitucionales}

La exégesis y hermenéutica del Pilar Europeo proclamado en la Cumbre Social de Gotemburgo se sitúa en la hoja de ruta trazada por el Presidente Juncker en el celebérrimo «Discurso sobre el Estado de la Unión», pronunciado el 9 de septiembre de $2015^{31}$. Las turbulencias de la zona euro exigieron la adopción de mecanismos de refuerzo y control de las economías de los países miembros de la GEE, que se saldaron con una constitución económica europea fortalecida y dotada de hiperrigidez normativa derivada en cuanto al dispositivo reforzado de tutela-garantía del euro, a costa de una depauperización de la dimensión social. En este contexto, se hacía necesario reforzar la integración positiva «redoblando los esfuerzos encaminados a conseguir un mercado laboral justo y verdaderamente paneuropeo», escenario donde se sitúa el desarrollo del PEDDSS adaptado a los cambios socio-laborales en curso y dirigido a la convergencia renovada de la zona euro (pp. 19-20 del discurso).

$\mathrm{Al}$ albur de esta declaración de intenciones, dos serían las principales connotaciones del Pilar, no exentas de importantes consecuencias en lo que a la definición y alcance de los derechos sociales supranacionales respecta. La primera, el Pilar no crea ni reconoce nuevos derechos sociales a escala europea, simplemente reafirma derechos que ya están presentes en el acervo de la UE y en el internacional, y los complementa para tener en cuenta nuevas realidades, esto es, ni siquiera los redefine. Tampoco rediseña el marco competencial UE-Estados Miembros (EEMM) en lo relativo a las políticas sociales y de empleo, por lo que se mantienen las dinámicas de coordinación social de tipo soft, en combinación con técnicas de orientación de políticas económicas de naturaleza hard. Además, al igual que la CDFUE distingue entre principios y derechos, reproduciendo las aporías de la divisibilidad. A saber, la confinación de la realización de los principios sociales a los colegisladores europeos y a los legisladores nacionales consagrando la ruptura del vínculo social de los derechos. La tutela se sitúa preferente en la voluntad política de los Estados y la Unión, una voluntad fuertemente condicionada por los parámetros de la nueva GEE reforzada y de la competencia internacional. En el espacio de estas variables se sitúa el valor de la solidaridad. Su campo de acción se inscribe en las dinámicas de la competencia y el monetarismo, haciéndose depender del funcionamiento del mercado

\footnotetext{
Balaguer Callejón, Francisco (Coord.). Constitucionalismo crítico. Liber amicorum Carlos de Cabo Martín. Valencia: Tirant Lo Blanch, pp. 137-242.

31 Disponible en: https:/publications.europa.eu/en/publication-detail/-/publication/6cd0b012-d637-11e6ad7c-01aa75ed71a1/language-es/format-PDF (consultado por última vez el 20.5.2018).
} 
interior su efectiva realización. Las políticas sociales nacionales también aparecen vinculadas a estas dinámicas, sus contenidos son los propios de la mejora de la productividad en términos competitivos. Inscritas directamente en la práctica de la competencia, no sólo se subordinan a aquella, sino que es ésta el único espacio para su actuación. Y, por lo que a los derechos sociales respecta, estos siguen configurándose como derechos condicionados tal y como se desprende de las bases normativas de los principios y derechos del Pilar perfiladas en el Preámbulo:

- los objetivos sociales del artículo 3 del Tratado de la Unión Europea (TUE), deben realizarse a través del mercado interior, la GEE y las previsiones del Protocolo sobre mercado interior y competencia, reafirmando la reconducción/ subordinación del modelo social a los principios del mercado y la constitución económica europea. A ello habría que añadir la omisión expresa de toda referencia al modelo social europeo tanto en relación con los objetivos sociales, como con la caracterización del proceso de integración y los valores sobre los que se fundamenta la Unión. De tal forma que el Tratado de Lisboa no hace sino acentuar la jerarquía de la integración negativa reforzándola a través de la inclusión del paradigma del mercado interior como referente donde el dispositivo social tiene sus límites. En esta perspectiva debe interpretarse la fórmula economía social de mercado altamente competitiva, que no implica una socialización de los objetivos de la UE que permita poner de relieve la voluntad de profundizar en la integración positiva. El aditamento «altamente competitiva» actúa la desvinculación de la economía social de mercado con el modelo social europeo, para conectarla con la constitución económica europea ${ }^{32}$.

- La cláusula social transversal del artículo 9 del Tratado de Funcionamiento de la Unión Europea (TFUE), tampoco permite articular espacios de autonomía de la integración positiva. Su carácter de criterio orientador a nivel político y de acción de las instituciones europeas en el ámbito de lo social impide yuxtaponer un vínculo social fuerte capaz de condicionar la prevalencia de los correlatos de la competitividad y la economía de mercado.

- La explícita referencia a los derechos sociales fundamentales reconocidos en la Carta Social Europea de 1961 (CSE), y en la Carta Comunitaria de los Derechos Sociales Fundamentales de los trabajadores, de 1989, que efectúa el artículo 151 del TFUE, contradice las garantías normativas de estos derechos en el constitucionalismo social. La dicción literal «teniendo presentes» comporta un reenvío a los textos que se conjuga con la confianza en el funcionamiento del mercado interior y la necesidad de mantener la competitividad de la economía de la Unión como condicionantes de la evolución de esta categoría de derechos. Ni son límites, ni tampoco les acompaña un valor teleológico de la acción de la Unión y los EEMM. Los intereses sociales que revisten la forma de objetivos (fomento del empleo, mejora de las condiciones de vida y trabajo, protección social adecuada, diálogo social y lucha contra las exclusiones) son el único objeto de tutela y oportunidad de satisfacción conectada a la lógica contumaz del mercado. La contradicción 
entre derechos sociales adscritos al intervencionismo social del Estado social, y derechos sociales condicionados por las exigencias del vínculo económico, es difícilmente objetable.

- Continúa el Preámbulo con la apelación al papel de los interlocutores sociales y el fomento del diálogo social del artículo 152 del TFUE. Una tímida y cauta formulación que comporta, todo lo más, una acción de promoción donde el diálogo social se perfila como concepto técnicamente poco riguroso, una disposición jurídicamente no vinculante, que responde al marco general y específico del desarrollo de la dimensión social europea desde una perspectiva favorable a la convergencia de las políticas sociales con los objetivos del mercado interior ${ }^{33}$.

- Las referencias a las disposiciones sociales de la Carta de Niza devienen inevitables en este inventario del acquis social de la Unión. En el Capítulo IV, la Solidaridad, se residencia el núcleo fuerte de los derechos sociales. Una lectura conjunta de su tratamiento, y las disposiciones generales de la Carta, confirman su devaluación jurídica. El componente más destructivo de la dimensión de garantía normativa de los derechos sociales está en la peculiar relación entre estos y la ley que determina el reenvío (artículo 52 CFUE - Alcance e interpretación de los derechos y principios-). Introduciendo la máxima, propia de la experiencia jurídica del siglo dieciocho, de que el contenido de los derechos encuentra en la ley su límite principal. De modo que las garantías proporcionadas no van más allá de cuanto ya ha sido garantizado por las legislaciones. La garantía se sitúa en el plano infraconstitucional supranacional o nacional, y no ya en la propia Constitución ${ }^{34}$.

- Finalmente, concluye la parte expositiva del Pilar con el recurso a una amalgama de preceptos del TFUE donde se combinan las libertades económicas de circulación (artículos 45 a 48 TFUE) y establecimiento (artículos 49 a 55 TFUE), con incidencia en la integración positiva, la igualdad salarial entre hombres y mujeres, (artículo 157 TFUE) la cohesión económica social y territorial (artículos 174 a 178 TFUE), y las orientaciones para el empleo (artículo 148 TFUE), entre otras. La significativa anomalía con la que se articula la relación entre las libertades económicas y los derechos de contenido social reproduce el modelo del constitucionalismo de mercado, resultado de la constitucionalización a escala europea de las libertades económicas sobre las que se fundamenta el paradigma del mercado interior. Esta caracterización de las libertades económicas fundamentales con respecto a los contenidos sociales las conecta directamente con los objetivos de la Unión. De este modo, el mercado, nuevamente, se constituye como eje central del proyecto europeo dotado, además, de especiales garantías.

La segunda connotación, y la más importante, consiste en que los principios y derechos interiorizados por el Pilar se aplicarán dentro de la sistemática de la GEE, en concreto, mediante el Semestre Europeo para la coordinación de políticas económicas y de

33 Jimena Quesada, Luis (2016): Social rights and policies in the European Union, cit., pp. 71-73.

34 Maestro Buelga, Gonzalo (2004): «Il costituzionalismo democratico sociale e la Carta dei diritti fondamentali dell'Unione Europea», Quaderni di Rassegna Sindacale, núm. 1, p. 122. 
los programas nacionales de reforma de los $\mathrm{EEMM}^{35}$. La integración de los derechos sociales en la renovada constitución económica europea no supone la asunción de la naturaleza dual que hemos apuntado. La ausencia de la dimensión conflictual esteriliza la constitucionalidad «europea» de los derechos. Tampoco la dimensión funcional desempeña la coordinación entre la demanda y la producción a escala europea. El constitucionalismo económico, adscrito a la autonomía del mercado, y el constitucionalismo social de la solidaridad competitiva son las bases materiales del constitucionalismo de mercado europeo, ámbito de actuación del Pilar. De ahí su estatus de condicionados o subordinados al vínculo económico que desplaza al vínculo social. Esto es, un nuevo significado y alcance de lo social en el espacio supranacional opuesto a las tradiciones del constitucionalismo social, lo que cuestionaría la propia existencia de la categoría de derechos sociales en el ordenamiento europeo ${ }^{36}$.

Siguiendo con la tesis de la configuración condicionada de los derechos sociales por la constitución económica europea renovada, sirva su reconducción a las bases jurídicas del conjunto de medidas de la nueva gobernanza económica que incrementan la conexión entre los procedimientos de supervisión multilateral del cumplimiento de las orientaciones generales para las políticas económicas de los EEMM y los procedimientos de control presupuestario. La garantía de la estabilidad macroeconómica como único referente en la definición de la política económica de la Unión, de acuerdo con el modelo de económica abierta y libre competencia (artículo 120 TFUE), y los principios rectores de saneamiento de las economías de la eurozona del artículo 119.3 TFUE (estabilidad de precios, finanzas y condiciones monetarias sólidas y balanza de pagos estable), son reflejo de la ausencia de un gobierno de la economía europeo, y, por ello, de una limitación de la capacidad de dirección económica de las orientaciones generales de la política económica tanto para los países miembros como para las propias instituciones europeas. La ausencia de mecanismos de intervención y redistribución social a escala europea como mecanismos correctores del mercado interior que minimicen el impacto de los vínculos del constitucionalismo de mercado, la competencia y el monetarismo, define los espacios de configuración y realización de los derechos sociales en el orden europeo. Su reconducción al terreno de los objetivos y las políticas reproduce el estigma de las normas programáticas que supone situarse fuera del estatus jurídico constitucional de estos derechos en el constitucionalismo social.

\subsection{Los contenidos sociales}

Los principios y derechos que componen el Pilar se estructuran en torno a tres categorías detalladas en los siguientes Capítulos:

- Capítulo I. Igualdad de oportunidades y de acceso al mercado de trabajo. Se incluyen: el derecho a una educación, formación y aprendizaje permanente

35 Garben, Sacha (2018): «The European Pillar of Social Rights: Effectively Addressing Displacement?», European Constitutional Law Review, núm. 14, pp. 216-217.

36 Maestro Buelga, Gonzalo (2008): «La inaprehensible ciudadanía social europea», Revista de Derecho Político, núm. 71-72, pp. 755-758. 
inclusivos y de calidad (01); la igualdad de trato y retribución entre mujeres y hombres (02 a y b); la igualdad de oportunidades de los grupos infrarrepresentados (03); y, el apoyo activo para el empleo (04 a, b y c). En este primer capítulo se integran los derechos formativos adscritos a las transiciones en el mercado laboral en el marco de la empleabilidad, siguiendo las coordenadas del derecho a trabajar vinculadas a la sociedad activa del Workfare state. La ruptura con las políticas pasivas de empleo del Estado social pone el acento en la responsabilidad de las personas en la búsqueda de un puesto de trabajo y en la adquisición de las capabilities necesarias para la participación proactiva en la sociedad. Desaparece el concepto de clase trabajadora, sustituyéndose por la más inocua expresión «toda persona», combinado con un léxico más propio del ámbito empresarial (mantener y adquirir capacidades; gestionar con éxito las transiciones) que diluye toda referencia al elemento conflictual. Con relación a la igualdad, se cosifica en las dinámicas de la igualdad de trato o formal, omitiéndose la desigualdad estructural sistémica de clase que vertebra la raza y el género, principal detonante de la histórica preterición femenina y racial. En esta tesitura se hace referencia a la igualdad salarial, dotándola así de un componente netamente económico en la visión utilitarista de la lucha contra el dumping social. Concluye el capítulo con la inclusión de ayudas activas para la búsqueda de empleo, formación y reciclaje, la garantía de empleo juvenil, y el asesoramiento individual de los parados de larga duración. De nuevo, se excluye toda referencia a la precariedad en la contratación, la devaluación salarial o la pérdida de garantías laborales como la descausalización del despido, como principales factores del desempleo y la pobreza de las clases trabajadoras.

- Capítulo II. Condiciones de trabajo justas: se hace referencia a los salarios (06a: derecho a un salario justo (06b) que evite la pobreza de los ocupados y se fije con transparencia y predictibilidad (06c); al derecho a la información sobre la condiciones de trabajo y la protección en caso de despido (07); al diálogo social y participación de los trabajadores (08); al equilibrio entre vida profesional y vida privada (09); a un entorno de trabajo saludable, seguro y adaptado, y protección de datos (10). Frente a la ausencia de la dimensión funcional del primer capítulo, este segundo apela a esa dimensión socio-económica de los derechos sociales que enlazaría con las tradiciones del constitucionalismo social. Sin embargo, la Comisión ha adoptado una aproximación más económica que social. La política para el empleo de la Unión, donde se insertarían los derechos y principios del Capítulo II del Pilar, se inspira en el principio de la libre competencia reconducida al incentivo de la actividad económica en detrimento de la protección del empleo. El tránsito de la tutela de la relación laboral a la tutela del mercado, «deberá garantizarse la flexibilidad necesaria para que los empresarios puedan adaptarse con rapidez a los cambios en el contexto económico», refleja el alcance de las condiciones de trabajo justas, esto es, la introducción de mecanismos de flexibilización que favorezcan la competencia económica. ${ }^{37}$ 
- Capítulo III. Protección e inclusión social: se combinan las referencias al derecho de asistencia y apoyo a los niños (11); la protección social (12); las prestaciones por desempleo (13); renta mínima (14); pensiones y prestaciones de vejez (13); sanidad (16); inclusión de personas con discapacidad (17), cuidados de larga duración (18); vivienda y asistencia para las personas sin hogar (19); y acceso a los servicios esenciales (20). Este último capítulo concentra el grueso de políticas asistenciales que han cobrado especial relevancia con la implosión de la crisis del capitalismo de casino. No obstante, su viabilidad, en términos de adopción de medidas legislativas específicas es cuestionable. Sirva de ejemplo la normativa autonómica social garantista impulsada por distintas Comunidades Autónomas en España en los últimos tiempos (función social de la propiedad, lucha contra la pobreza energética, entre otras), y su paralización por el ejecutivo español, con el posterior refrendo de la jurisprudencia del Tribunal Constitucional, en garantía del vínculo económico europeo $^{38}$. Precisamente, la penalización de los vínculos sociales al mercado impulsada por la GEE, considerando el gasto social público como equivalente a una desincentivación del uso de recursos económicos, ha trasladado la competitividad a los derechos nacionales reduciendo las garantías tradicionales de los sistemas de protección social. Este ha sido el factor detonante de la pobreza infantil, el desempleo de larga duración, los recortes en las rentas mínimas de inserción, las pensiones, los sistemas sanitarios y la atención a la dependencia. Derechos y principios que este tercer capítulo pretende ahora fortalecer a través medidas vinculantes específicas que se han de adoptar en consonancia con el mismo marco, la constitución económica europea, que ha generado su devaluación al mínimo asistencial.

En definitiva, las intenciones del Pilar de corregir la asimetría de la integración positiva europea no son factibles en términos sustantivos en lo que atañe a la política social, vistas las propias limitaciones del Título $\mathrm{X}$ que circunscribe los objetivos sociales a las dinámicas del mercado interior y la competitividad de la economía de la Unión. Pero, sobre todo, las carencias del Pilar son ilustrativas en lo referente a su incapacidad para corregir el desplazamiento de la toma de decisiones sociales democráticas al juez europeo y a las instituciones intergubernamentales de la Unión ${ }^{39}$.

\section{LA DIMENSIÓN OBJETIVA DE LOS DERECHOS CIVILES Y POLÍTICOS EN LA JURISPRUDENCIA DEL TRIBUNAL EUROPEO DE DERECHOS HUMANOS: DE LA (IN) DIVISIBILIDAD A LA ACCESORIEDAD}

El juez de Estrasburgo ha adquirido una notoriedad inusitada al compás de la crisis como garante de la dimensión objetiva de los derechos del $\mathrm{CEDH}$, construyendo una

38 LASA López, Ainhoa (2017): «El modelo social autonómico del constitucionalismo de mercado: cuando la garantía de la igualdad real se sustituye por la del coste de financiación», Revista valenciana d'estudis autonòmics, núm. 62, pp. 123-148.

39 Garben, Sacha (2018): «The European Pillar of Social Rights: Effectively Addressing Displacement?», op.cit., pp. 227-230. 
línea pretoriana de defensa «accesoria» de determinados derechos sociales de prestación. Esta expansión de los contenidos de los derechos fundamentales civiles y políticos del Convenio ha sido objeto de especial atención por la doctrina, que ha visto la oportunidad de apuntalar la tesis de la indivisibilidad de los derechos humanos, de su indefectible vinculación. Y, principalmente, la posibilidad de hacer exigibles, en determinadas circunstancias, a los poderes públicos los derechos sociales de prestación que los textos fundamentales, como el español, confinan al limbo de la programaticidad ${ }^{40}$.

Aunque el CEDH no prevé tutela alguna para los derechos sociales, haciendo coincidir los derechos humanos con las libertades fundamentales, en una incipiente línea jurisprudencial iniciada el 19 de octubre 1979 con el Caso Airey contra Irlanda, comenzó a manifestar las implicaciones socio-económicas de algunos derechos civiles y políticos. Emergían así los determinantes sociales como factor a tener en cuenta en la interpretación de los derechos del Convenio. En este caso, una ciudadana irlandesa en una situación económica precaria alegó la vulneración del derecho a un juicio justo (artículo 6.1), al no contemplar la legislación del país de origen el asesoramiento jurídico gratuito, circunstancia que le impidió iniciar un procedimiento judicial de separación. El reconocimiento del principio de la protección efectiva de los derechos, y su corolario de la interpretación evolutiva de la Convención aducida por el Juez de Estrasburgo en el caso Marckx, de 13 de junio de 1979, inició la senda de una jurisprudencia inclusiva de las dinámicas de orden social de los derechos humanos. La protección no quimérica de algunos derechos procesales (derecho a un proceso equitativo) y sustantivos (artículo 1 del Protocolo $\mathrm{n} .{ }^{\circ} 1$, protección de la propiedad; artículo 2, derecho a la vida; artículo 8, derecho al respeto de la vida privada y familiar; artículo 14, prohibición de discriminación) del Convenio, en conjunción con las técnicas de la hermenéutica extensiva o por conexión y de las obligaciones positivas del Estado, representan el fundamento jurídico de la justiciabilidad de ciertos derechos sociales prestacionales (protección de la salud, pensiones, vivienda) ante esta instancia europea ${ }^{41}$.

Conviene advertir que no es objeto de este trabajo detenerse en el análisis detallado de las sentencias dictadas por el CEDH en la materia que nos ocupa, pues es una cuestión suficientemente abordada por la doctrina. Desde otra perspectiva metodológica, lo que interesa aquí poner de relieve son las carencias de una interpretación de los derechos que, aunque desvinculada del dogma el vínculo económico, ahonda en la divisibilidad más que en la superación de las connotaciones normativas regresivas de los derechos sociales como normas en blanco. Para ello, sí tomaremos como referente algunos de los

40 López Guerra, Luis (2015): «Crisis económica y derechos humanos. Una nota de jurisprudencia», Teoría y Realidad Constitucional, núm. 36, pp. 399-414. CARmona Cuenca, Encarna (2017): «Derechos sociales de prestación y obligaciones positivas del Estado en la jurisprudencia del Tribunal Europeo de Derechos Humanos», Revista de Derecho Político, núm. 100, pp. 1209-1238. Cubero Marcos, José Ignacio (2017): «La vis expansiva de los derechos fundamentales y su incidencia en la configuración y exigibilidad de los derechos sociales», Revista Española de Derecho Constitucional, núm. 110, pp. 105-140.

41 Pérez Alberdi, M. ${ }^{a}$ Reyes (2011): «La jurisprudencia social del Tribunal Europeo de Derechos Humanos», LEX SOCIAL-Revista de Derechos Sociales, núm.1, p. 94. Para un análisis detallado de la interpretación por conexión de las garantías procesales y sustantivas del Convenio y la protección de derechos sociales vid: López GUERRA, Luis (2015): «Crisis económica y derechos humanos. Una nota de jurisprudencia», op.cit., pp. 401-408. Para una reflexión pormenorizada de la doctrina de las obligaciones positivas del Estado y la eficacia jurídica de los derechos sociales de prestación vid: CARMONA CuENCA, Encarna (2017): «Derechos sociales de prestación y obligaciones positivas del Estado en la jurisprudencia del Tribunal Europeo de Derechos Humanos», op.cit., pp. 1228-1234. 
razonamientos teóricos que subyacen en la jurisprudencia del TEDH, en particular, los relativos al margen de apreciación reconocido a los Estados en la aplicación de las obligaciones de la Convención. Técnica que recuerda al debate entre la constitucionalidad de los derechos sociales y la discrecionalidad del legislador. Desde esta óptica, merecen especial atención las demandas planteadas ante el Tribunal de Estrasburgo con ocasión de los recortes en gasto social por parte de países miembros de la eurozona.

En los casos Da Conceição Mateus contra Portugal y Santos Januário contra Portugal (Solicitudes núm. 62235/12 y núm. 57725/12), la cuestión a dilucidar era la compatibilidad de las reducciones de los pagos a las pensiones de los demandantes, ciudadanos portugueses, con el artículo 1 de Protocolo n. ${ }^{\circ} 1$ (Protección de la Propiedad). La reducción producida en el año 2012 como resultado de los recortes al gasto público portugués, tenía su causa en el Programa de Ajuste económico negociado en mayo de 2011 por el gobierno luso con la UE, los países del eurosistema, y el Fondo Monetario Internacional. Para examinar la potencial incidencia de los recortes en la garantía de la propiedad contemplada por artículo 1 del Protocolo n. ${ }^{\circ} 1$ del Convenio, el Tribunal valoró como cuestión esencial si con los recortes las autoridades portuguesas habían alcanzado un equilibrio justo entre el interés general de la comunidad y la protección de los derechos individuales de la persona. La decisión finalmente adoptada fue que las reducciones de las pensiones habían sido una restricción proporcionada del derecho a la protección de la propiedad de los demandantes, considerando los problemas financieros excepcionales a los que Portugal se enfrentó en aquel momento, y la naturaleza limitada y temporal de los recortes de pensiones. El Tribunal no entró a valorar, como si lo hiciera el Tribunal Constitucional de Portugal, que una reducción equivalente no se hubiera llevado a cabo en el sector privado de las pensiones. En una decisión similar, dos años más tarde, en 2015, Da Silva Carvalho Rico v. Portugal (solicitud núm. 13341/14), el TEDH apuntala el criterio de la naturaleza temporal y limitada en el tiempo del recorte en la pensión de la demandante, atendiendo a la situación coyuntural por la que atravesaba Portugal y los compromisos de ajuste adquiridos en el marco de la nueva GEE, para inadmitir la demanda.

A diferencia del caso Guberina contra Croacia (Solicitud núm. 23682/13), en los dos asuntos que se acaban de señalar, el TEDH no consideró si la medida económica de recorte de las pensiones adoptada por el ejecutivo luso se aplicó o no de manera discriminatoria (véase párrafo 73 de la decisión Guberina), máxime teniendo en cuenta que estas reducciones no se aplicaron al régimen privado de pensiones. Se podría contra argumentar que en el asunto Guberina la denegación del beneficio fiscal, exención del impuesto de compraventa de un bien inmueble que contaba con un ascensor, afectaba a un menor con diversidad funcional física y psíquica, y, por ende, particularmente vulnerable. Vulnerabilidad que, al parecer, no concurría en el caso de los demandantes pensionistas. Si bien la aplicación del principio de la interpretación evolutiva de la Convención hubiera sido base suficiente para valorar si esa proporción reducida de la pensión no podía conducir a una situación de vulnerabilidad, teniendo en cuenta el fenómeno de la pobreza en la tercera edad que asola al continente europeo. Esto es, una adecuación del Convenio a nuevas realidades de marginación y vulnerabilidad desconocidas o ausentes en el momento de su promulgación ${ }^{42}$.

42 No obstante, convenimos con Jimena Quesada en que hay tener en cuenta las propias limitaciones de la sistemática formal del Convenio y sus Protocolos. En particular, «intentando ofrecer una lectura en clave más 
En todo caso, lo relevante estos planteamientos, en lo que a los derechos sociales de prestación atañe, es la determinación del alcance del margen de apreciación estatal para la reducción, denegación o interrupción del contenido de la prestación social. Tres consideraciones al respecto: en primer lugar, también en el argumentario del TEDH derechos sociales y costes económicos se sitúan en el mismo nivel. En segundo lugar, aunque, en determinadas circunstancias, es posible derivar derechos sociales de prestación de los derechos del convenio, el reconocimiento de los primeros parte de su necesaria conexión con los derechos sustantivos y procesales de la Convención. Esta inautonomía de los derechos sociales supone una desocialización de los derechos sociales y su reconducción a otras bases materiales, las de los derechos civiles y políticos del convenio, luego no hay indivisibilidad sino divisibilidad manifiesta, pues solo cuando la privación de las prestaciones sociales afectan al núcleo intangible de los derechos humanos, opera su reconocimiento secundario o accesorio del principal. En tercer lugar, los casos donde ha transcendido la eficacia jurídica del derecho prestacional se vinculan a supuestos de vulnerabilidad de los sujetos afectados por la restricción de un derecho individual ${ }^{43}$. De modo que, todo lo más, los derechos sociales se conectan con la procura existencial que Forsthoff defendía para expulsar a lo social del enunciado constitucional. En resumen, frente a los Derechos Sociales del pacto del constitucionalismo social, nos encontramos con los derechos sociales asistencializados de la Convención. Una lectura de mínimos a la que, sin embargo, hay que poner en alza, sobre todo, si hacemos una comparativa con la condicionabilidad que experimentan los derechos sociales en el ordenamiento jurídico europeo.

\section{CONCLUSIONES FINALES}

\section{Los derechos sociales accesorios de la jurisprudencia de Estrasburgo, y los derechos sociales condicionados del juez de Luxemburgo: las lecturas de la (des)constitucionalización}

En la relación derechos sociales-libertades económicas, el juez de Estrasburgo aplica un razonamiento distinto en cuanto a la ponderación de los intereses en conflicto. Si para

positiva con respecto al proceder inmovilista sobre situaciones de precariedad, o reacio en el terreno de la discapacidad, es pertinente señalar que ambas posturas del TEDH tal vez denoten un alarde de realismo, en el sentido de no poder abarcar más allá de lo que el texto convencional y sus Protocolos le marcan». Jimena Quesada, Luis (2015): «El Comité Europeo de Derechos Sociales: sinergias e impacto en el sistema internacional de derechos humanos y en los ordenamientos nacionales», Revista Europea de Derechos Fundamentales, núm. 25, pp.110-111.

43 En este sentido, la reciente decisión del TEDH, caso de ČAKAREVIĆ contra Croacia (solicitud no. 48921/13), de 26 de abril de 2018. La demandante alega la vulneración del derecho a la protección de la propiedad al ser obligada a devolver una ayuda por desempleo por enriquecimiento ilícito al no cumplir las condiciones para su concesión durante un periodo de tiempo determinado. El juez de Estrasburgo valora la precaria situación económica y de salud de la demandante para concluir que incluso la devolución de la cantidad indebidamente recibida pondría en riesgo su subsistencia (apartado 89).

De ahí que López Guerra se interrogue, a propósito de la relación derechos sociales-obligaciones positivas, si esta técnica tiene cabida en términos más ambiciosos «es decir, como referidos a situaciones de tipo general, aún sin los caracteres de gravedad y urgencia de los supuestos señalados y respecto de derechos generalizados a prestaciones típicos del Welfare State». LóPEz GuerRA, Luis (2015): «Crisis económica y derechos humanos. Una nota de jurisprudencia», op.cit., p. 404. 
el TEDH lo sustancial es la mayor o menor incidencia para la efectiva realización de los derechos y libertades fundamentales del texto de la Convención, para el TJUE lo relevante es la afectación a los principios estructurales del mercado interior y la libre competencia. Nótese que ya la propia categoría de libertades económicas difiere de la propia de derechos humanos. De hecho, en el ámbito del ordenamiento europeo las libertades económicas tienen el mismo rango que los derechos fundamentales, compartiendo con estos últimos los presupuestos de valor. A diferencia de las constituciones nacionales, donde las libertades económicas no comparten el mismo rango de fundamentalidad asignado por el espacio europeo y deben de ceder frente a instancias diversas dedicadas a la tutela de la persona en la complejidad de sus relaciones sociales. Tal resultado interpretativo se manifiesta en el reconocimiento sustancial de un derecho subjetivo en el interior de las situaciones de libertad, y, por ende, en la calificación de las libertades económicas como derechos fundamentales. Por lo tanto, actúan de vínculo y limitación a las regulaciones del legislador nacional en el orden socio-económico europeo ${ }^{44}$.

Una concepción que ha desempeñado un papel determinante como mecanismo de legitimación del mercado interior y la GEE. Esta técnica jurisprudencial de singularizar a las libertades económicas vinculadas a las garantías del mercado con respecto al resto de los derechos, tiene especial incidencia en el caso de los derechos sociales que encuentran dificultades en un contexto jurídico débil. No obstante, se trata de algo plenamente coherente con la especificidad normativa del constitucionalismo económico, dado que son las libertades económicas como instrumento privilegiado debido a su carácter fundamental, las que refuerzan la tutela de la competencia y la centralidad del mercado. Así, han sido frecuentes las situaciones en las que el TJCE ha procedido a la tutela de los derechos sociales en función de la tutela de las libertades económicas. Es decir, estaríamos en presencia de una tutela indirecta que encuentra en las libertades económicas y no en los derechos sociales, el bien jurídico determinante de la directa protección ${ }^{45}$.

Este planteamiento coincide, inicialmente, con la naturaleza accesoria de los derechos sociales en las decisiones del Tribunal de la Convención. De hecho, tanto en el ámbito convencional como en el de la Unión la conexión derechos sociales-derechos civiles y políticos del Convenio, y derechos sociales - libertades económicas, se caracteriza en el primero por el margen de apreciación de los Estados, y, en el segundo, por la reserva de lo razonable y de lo posible, modulando el espacio de intervención de estos derechos que se difiere a la discrecionalidad del ejecutivo o legislativo de los EEMM. De modo que, en sendos razonamientos se observa una funcionalidad del vínculo social, eso sí, tangencial o más difusa, en las argumentaciones del juez de Estrasburgo, mientras que para el juez de Luxemburgo esa naturaleza funcional sería directa.

Paralelamente, la técnica de la interpretación extensiva de los derechos y libertades fundamentales convergería con la técnica de la comunicación empleada por el TJUE en una línea jurisprudencial constante en materia de libre circulación de trabajadores y su conexión con los regímenes públicos de base. En esta, el pleno acceso a los derechos

44 Oliver, Peter; Roth, Wulf-Henning (2004): «The internal market and the four freedoms», Common Market Law Review. Vol. 41, núm. 2, pp. 407-441.

45 Poiares Maduro, Miguel (1999): «Striking the elusive balance between economic freedom and social rights in the EU», en Alston, Philip; Bustelo, Mara; Heenan, James (Ed.). The EU and Human rights. Oxford: Oxford University Press, pp. 449-472. 
prestacionales para el trabajador comunitario y su familia se articulan desde una perspectiva de directa vinculación con la libertad económica de circulación, como derechos de comunicación que carecen de una directa conformación autónoma. Los imperativos de la constitución económica europea evitan una consideración autónoma de los derechos prestacionales y determinan también la debilidad de su estatus normativo, condicionado por la dinámica de la integración negativa ${ }^{46}$.

Empero, ahí terminarían las coincidencias entre Tribunales. Como hemos señalado, para el TEDH las exigencias del vínculo económico ocupan una posición menos predeterminante, sobre todo, cuando el sujeto demandante está en una situación de vulnerabilidad, como en el caso de Guberina ${ }^{47}$. A su vez, el hilo argumental parece dar cobertura a lo que se ha venido a denominar «la irreversibilidad de las conquistas sociales», sin sancionar expresamente la teoría de Hesse ${ }^{48}$, y con importantes matices, cuando apostilla que desarrollada la regulación (sistema de protección) social que corresponda, las autoridades competentes teniendo en cuenta las circunstancias sociales y económicas del momento, podrán realizar alteraciones siempre que el contenido esencial de la regulación establecida se mantenga ${ }^{49}$. Esto es, el alcance de la garantía de las regulaciones sociales establecidas se limita al núcleo del derecho humano para cuya efectividad la regulación social es esencial, y, por ello, ese aspecto, en la media en que es esencial, ya no sería susceptible de disponibilidad legislativa.

Por otro lado, en el ámbito europeo el desconocimiento de la naturaleza constitucional de los derechos sociales resulta tanto más gravosa porque, a diferencia de la Convención, si hay un reconocimiento explícito, al menos formal, de los derechos sociales producido tras la promulgación de la CDFUE que adquiere, además, con la entrada en vigor del Tratado de Lisboa una vinculación jurídica igual a la de los Tratados (artículo 6.1 TUE). Con todo, ya se ha señalado que la Carta de Niza está en sintonía con el modelo jurídico político del constitucionalismo de mercado, actuando una recomposición de la noción de derechos sociales notoria en aquellos pronunciamientos en los que el juez de Luxemburgo ha recurrido a la Carta. En concreto, en la Sentencia de 15 de enero de 2015, asunto C-176/12, el argumento principal determinante de la inaplicación de una disposición de derecho originario, como es el artículo 27 de la CDFUE, fue su insuficiencia "para conferir a los particulares un derecho subjetivo invocable como tal» (apartado 49); ni siquiera una vez precisado por una norma de derecho secundario (Directiva 2002/14/CE, por la que se establece un marco general relativo a la información y consulta de los trabajadores en la Comunidad Europea), es decir, tampoco una vez actuada la interpositio del colegislador europeo. Un razonamiento que reconduce a los derechos sociales a un estado de Reflexrechte.

46 Giubboni, Stefano (1998): «Libertá di circolazione e protezione sociale nell’Unione Europea», Giornale di Diritto del Lavoro e di Relazioni Industriali, núm. 77, p. 85.

47 En claro contraste con los pronunciamientos del TJUE en materia de solicitud de prestaciones asistenciales por la ciudadanía europea económicamente inactiva, donde la preocupación por el llamado turismo social, y la consiguiente carga económica adicional para los sistemas nacionales de Seguridad Social, ha desempeñado un papel crucial en las líneas argumentales utilizadas. Sirva como paradigma la Sentencia de 11 de noviembre de 2014, Elisabeta Dano, Florin Dano y Jobcenter Leipzig, C-333/13.

48 Hesse, Konrad, citado por Parejo Alonso, Luciano (1983): Estado Social y Administración Pública. Los postulados constitucionales de la reforma administrativa. Madrid: Civitas, pp. 53-55.

49 En este sentido, LóPEz Guerra, Luis (2015): «Crisis económica y derechos humanos. Una nota de jurisprudencia», op.cit., p. 405. 


\section{Pilar Europeo de Derechos Sociales y Convenio Europeo de Derechos Humanos: una relación asintónica}

A modo de consideración conclusiva podemos señalar que la respuesta a la pregunta de si el Pilar puede ser un revulsivo para superar la caracterización como accesorios de algunos derechos sociales de prestación en la jurisprudencia del TEDH, es a todas luces negativa. La principal causa no hay que buscarla en las propias limitaciones del texto convencional para tutelar la naturaleza de compromiso que subyace a los derechos sociales, sino en la negación que de las bases materiales del Estado social realiza el orden europeo. Como ya se ha apuntado, el Pilar se limita a consolidar el acervo social de la Unión con la consiguiente caracterización de los derechos sociales como objetivos o políticas insertos en el mercado interior y la GEE, una configuración condicionada por el vínculo económico que los sitúa en un estadio evolutivo inferior al conferido por el juez de Estrasburgo si bien lo social, en sus razonamientos, cede cada vez mayores espacios a la asistencialización, efecto distinto al que se derivaría del vínculo social como hilo argumental. Ahondando en la tesis de la falta de sintonía entre la Convención y el documento político del Pilar, cabría hacer alusión a la omisión intencional del TJUE de la jurisprudencia del Comité Europeo de Derechos Sociales (CEDS), «frente a la retroalimentación entre el TEDH y el CEDS» ${ }^{50}$.

Por otra parte, se ha puesto de relieve que el Pilar podría contribuir a potenciar la integración positiva de la Unión, al ir, en algunos aspectos, más allá que la CDFUE ${ }^{51}$. Entre otros: el Pilar incluye el derecho a un salario justo (06); el derecho a una prestación de renta mínima (14); o el derecho a cuidados de larga duración (18), que la Carta de la UE, como tal, no contiene ${ }^{52}$. A pesar de ello, las bondades de este análisis decaen desde su propia consideración sustantiva. Tomemos con referencia uno de los derechos sociales de prestación que mayor regresión ha experimentado en las últimos años, como es la pensión. Este derecho se contempla en el artículo 34.1 CDFUE, y en el artículo 15 del Pilar. La formulación en este último, siguiendo la tesis descrita, parece más ambiciosa al reconocer que la cuantía ha de ser acorde a unas contribuciones que garanticen una renta adecuada. La cuestión inmediata sería ¿Podría este derecho, si finalmente fuera implementado, servir de base habilitante para el TEDH en relación a la dimensión social de propiedad?

Planteada la pregunta en estos términos, y reconocidas las sinergias entre el TEDH y la CSE, la tesis de la mejor protección «accesoria» social parece tener cabida. Pero, ¿realmente el derecho a una pensión de jubilación del Pilar ofrece una mayor garantía que la prevista en la CDFUE? Aquí reside el nudo gordiano de la cuestión. La sistemática del Pilar se ha de cohonestar con los principios prescriptivos del vínculo económico

50 Jimena Quesada, Luis (2015): «El Comité Europeo de Derechos Sociales: sinergias e impacto en el sistema internacional de derechos humanos y en los ordenamientos nacionales», op.cit, p. 111.

51 Garben, Sacha (2018): «The European Pillar of Social Rights: Effectively Addressing Displacement?», op.cit., p. 221.

52 En la CDFUE, el salario adopta una concepción formal conectada a la prohibición de discriminación entre mujeres y hombres (artículo 21.1); la renta mínima se contempla con la denominación de ayuda social sin la apostilla de «adecuada», y la dinámica de la lucha contra la desigualdad estructural que el Pilar concreta en la "garantía de una vida digna». Con respecto a los cuidados de larga duración, la Carta reconoce el acceso a los servicios sociales que garantizan una protección en casos como la dependencia (artículo 34.1), pero sin precisar, como sí hace el Pilar, que este acceso sea asequible y de buena calidad, en particular de asistencia a domicilio y servicios comunitarios (18) 
europeo que actúa operando la subordinación de los contenidos sociales, desde la perspectiva de su condicionamiento por las dinámicas de la integración negativa. Además, se trata de principios prescriptivos para los EEMM de la nueva GEE que son, a su vez, quienes deben adoptar las medidas necesarias para que el contenido del derecho a la pensión del Pilar sea jurídicamente vinculante. Esta apreciación de legalidad del derecho positivo que reproduce el artículo 34.1 CDFUE, termina cercenando el mejor contenido social posible del artículo 15 del Pilar; al reservarse su modalidad de ejercicio a las disciplinas de la legislación y la praxis nacional, condicionadas por la constitución económica europea. Precisamente, es en el ámbito legal donde se materializan las transformaciones que guardan una vinculación directa con los parámetros del constitucionalismo del mercado. Los ejecutivos y legisladores nacionales reproducen, fielmente, los estándares mínimos de protección previstos por la panoplia instrumental de la GEE. Si a ello añadimos el margen de apreciación reconocido por el TEDH, los límites para evitar la aceptación de la garantía y protección constitucional de los derechos sociales son claros. El amplio margen de maniobra de los ejecutivos y legislativos nacionales, unido a la indeterminación o incompletitud de los derechos y principios sociales enunciados por el Pilar los traslada a la mera retórica «constitucional» a escala europea, a su consumación.

$$
* * *
$$

TITLE: Potentialities of the European Pillar of Social Rights in the Judge of Strasbourg's jurisprudential praxis: between the heterarchy social link-economic link and the dysfunctionality

ABSTRACT: The use of the principles of effective protection and evolutionary interpretation has generated a prominent casuistry of accessory recognition of some social rights by the European Court of Human Rights. On the other hand, the European Pillar of Social Rights, with its objective of improving the positive integration of the euro system, seems to expand the content of some social rights contemplated by the EU Charter of Fundamental Rights. Following these coordinates, the objective of this article is to reflect on the role of Pilar in the line of reasoning of guaranteeing the objective dimension of buman rights of the Convention developed by the judge of Strasbourg.

RESUMEN: El recurso a los principios de la protección efectiva y la interpretación evolutiva ha generado una prominente casuística de reconocimiento accesorio de algunos derechos sociales de prestación por parte del Tribunal Europeo de Derechos Humanos. Paralelamente, el Pilar Europeo de Derechos Sociales, con su objetivo de mejorar la integración positiva del euro sistema, parece ampliar el contenido de algunos derechos sociales contemplados por la Carta de Derechos de la Unión. Siguiendo estas coordenadas, el objetivo del presente artículo es reflexionar sobre el papel del Pilar en la linea argumental de la garantía de la dimensión objetiva de los derechos humanos de la Convención desarrollada por el juez de Estrasburgo.

KEY WORDS: programmatic norms, European economic governance, secondary rights, conditional rights, social rights.

PALABRAS CLAVE: normas programáticas, gobernanza económica europea, derechos accesorios, derechos condicionados, derechos sociales.

FECHA DE RECEPCIÓN: 13.06.2018

FECHA DE ACEPTACIÓN: 13.09.2018 
